\title{
Análisis Crítico del Discurso (ACD) de la representación boliviana en las noticias de la prensa diaria de cobertura nacional: El caso de El Mercurio y La Tercera*
}

\author{
Rodrigo Browne Sartori \\ Pamela Romero Lizama**
}

Resumen: En los diálogos entre las diferentes voces que aparecen en los medios de comunicación la relación es desigual, y es posible ver cómo se da preponderancia a algunos actores sociales en desmedro de otros. Dicha relación se vuelve todavía más compleja cuando los participantes son de culturas diferentes. La siguiente investigación pretende, por medio de una herramienta metodológica ligada al Análisis Crítico del Discurso (ACD) desarrollado por Teun van Dijk, develar los procesos y formas de representación con los que se mira a los bolivianos, a través de las noticias de los diarios de cobertura nacional El Mercurio y La Tercera, durante el mes de junio de 2008. El estudio, por tanto, intenta descubrir cómo la prensa escrita colabora en la representación y construcción de la realidad (Berger y Luckmann 1972) intercultural de sus lectores, formando y promoviendo prejuicios y estereotipos socioculturales.

Palabras clave: Bolivia-Chile, interculturalidad, periodismo, Análisis crítico del Discurso (ACD), construcción social de la realidad.

\section{Critical Discourse Analysis (CDA) of the bolivian representation in the chilean nationwide daily press news. The case of the newspapers El Mercurio and La Tercera}

Abstract: In the dialogues among the different voices that appear in the communication media there is an unequal share and it is possible to see that preponderance is given to some social actors declining others. Such relationship becomes even more complex when participants belong to different cultures. The following research intends, through a methodological tool related to the Critical

\footnotetext{
* Este trabajo forma parte del proyecto FONDECYT N 11070062 “Comunicación intercultural y periodismo intercultural: análisis crítico de la construcción social de la realidad a través de la representación mapuche y peruano-boliviana en las noticias de la prensa diaria de cobertura nacional (Copesa y El Mercurio) - (2008)”. Comisión Nacional de Investigación Científica y Tecnológica (CONICYT). Ministerio de Educación de Chile.

** Universidad Austral de Chile (UACH), Valdivia, Chile. Email: rodrigobrowne@uach.cl y pamerome@gmail.com
} 
Discourse Analysis (CDA) developed by Teun van Dijk, to unveil the processes and representation forms with which the bolivians are looked upon, on the news of nationwide newspapers El Mercurio and La Tercera, during the month of june 2008. The study, therefore, sets up to reveal how the written press collaborates with the representation and construction of intercultural reality (Berger y Luckmann, 1972) of its readers, setting up and promoting sociocultural prejudices and stereotypes.

Key words: Bolivia-Chile, intercultural journalism, Critical Discourse Analysis (CDA), social construction of reality.

\section{Análise Crítica do Discurso (ACD) da representação boliviana nas notícias da imprensa jornalística de cobertura nacional: o caso do El Mercurio e La Tercera}

Resumo: Nos diálogos entre as diferentes vozes que aparecem nos meios de comunicação, a relação é desigual e é possível ver como a ênfase é colocada em alguns atores sociais em detrimento de outros. Essa relação se torna ainda mais complexa quando os participantes são de diferentes culturas. A presente pesquisa pretende, Por meio de uma ferramenta metodológica ligada à análise crítica do discurso (ACD) desenvolvida por Teunn van Dijk, desvelar os processos e formas de representação com que se olha os bolivianos, atrav es das notícias dos jornais de cobertura nacional El Mercurio e La Tercera, durante o mês de junho de 2008. O estudo visa, portanto, descobrir como a imprensa colabora com a representação e construção da realidade (Berger e Luckmann, 1972) intercultural seus leitores, formando e promovendo os preconceitos e estereótipos sócio-culturais.

Palavras-chave: Bolívia, Chile, interculturalidade, jornalismo, análise de discurso crítica (ADC), a construção social da realidade.

Recibido: 28.07.2009

Aceptado: 21.12.2009

$* * *$

\section{La Noticia como discurso ideológico}

Como es de conocimiento general, los medios de comunicación se jactan de entregar hechos y acontecimientos presentados como "verdades" que se sostienen sobre un mismo discurso ético-político y social. Preceptos fundamentales como la mirada objetiva y el fiel reflejo de la realidad mantienen viva la credibilidad del medio frente a los potenciales auditores, televidentes y lectores. Pero quien quiera ir un poco más allá, se puede percatar de que la realidad mediática/pública no siempre es así y no siempre es como ellos mismos la pretenden plantear.

Uno de los pilares que sustenta esta investigación es el de tratar de aproximarse a una desmitificación de "las noticias", despojándolas de su halo de verdad incuestionable que les permite reinar en las lógicas del piper meter desde una tribuna coronada por un aparente poder mediático. Simulación que se catapultó a partir del rótulo amplio y general de comunicaciones de masas. La idea, por tanto, es detenerse en el carácter vacío que condice 
con cada información emitida, publicada o difundida para no sólo quedarse con el aquí y ahora de un traspase de información lineal y muy poco dinámico (Sierra 1999). Sino hurgar entre los discursos de las diferencias que quedan escondidos en las redacciones de los periodistas y/o en las líneas editoriales de los mismos medios: "Los periodistas son, como todas las personas, constructores de la realidad de su entorno. Pero además dan forma de narración a esta realidad y, difundiéndola, la convierten en una realidad pública” (Rodrigo 1989: 15).

El sólo hecho de que la realidad no puede mantenerse ajena a quien la interpreta o la interioriza hace que la famosa “objetividad” de los medios se ponga en tela juicio. Los tiempos así lo han subrayado y las escuelas de periodismo -por lo menos las más actualizadas en Chile- se están desmarcando del mito de la objetividad y están abriendo puertas dialógicas a versiones más deslucidas de ésta, jugando, por ejemplo, con “objetividades subjetivadas" y viceversa o haciendo parte del debate a proyecciones teóricas con mayor profundidad como son las de subjetivación y hermenéutica, entre otras. La objetividad como tal ya no tiene cabida ni en las propias asignaturas castas, estructuradas y unidireccionales que se conocen bajo el nombre de "periodismo informativo" y que -en la lógica de lo que llama la escuela de São Paulo como los medios de incomunicación- se puede encontrar perfectamente en uno de los objetos de estudio de este trabajo, como es el diario El Mercurio y su consorcio periodístico con presencia a lo largo del país.

Por ello, unas de las prioridades de la presente investigación es formalizar discusiones de este nivel en los circuitos científicos nacionales. Espacio que permita dar tribuna a diálogos y debates culturales como, por ejemplo, el que se pretende activar en el proyecto FONDECYT No 11070062 "Comunicación intercultural y periodismo intercultural: análisis crítico de la construcción social de la realidad través de la representación mapuche y peruano-boliviana en las noticias de la prensa diaria de cobertura nacional (Copesa y El Mercurio)” del cual, en lo que corresponde a la relación boliviana-chilena, este artículo es uno de sus últimos resultados.

En este sentido, tampoco hay que pecar de ingenuo y es fundamental partir de la indudable base que la organización -dentro de la que el periodista trabaja- siempre ejerce influencias en el informe producido $\mathrm{y}$, por ende, en el discurso final que llega a los públicos entendidos hoy como consumidores de informaciones en formato noticia. Pero, difícilmente, en el ámbito periodístico se reconoce que lo que se realiza es una construcción de la realidad social y que, en muchas ocasiones, se escapa de la jabonosa incapacidad de definir la noción de "realidad". La realidad como tal no existe y si existe cada uno de nosotros podemos ir adaptándola de acuerdo a los intereses personales-colectivos. La realidad o, más bien, las realidades del Chile de la dictadura no son las mismas que las del país en postdictadura y las versiones sobre este nuevo periodo varían en relación a cuántas realidades e interpretaciones de éstas puedan surgir. Por ello, un deber del medio es asumir que en su discurso existe un alto grado de in- 
fluencia que puede incluso cambiar percepciones y formas de estar en el mundo (Vázquez 2003). Es necesario, en síntesis, estar abiertos al diálogo desde una racionalidad comunicativa que asuma a la crítica como parte de sus puntos de vista, pues sólo desde la autocrítica se pueden derribar las fronteras culturales estimuladas a partir de "la verdad" y "la realidad" que construyen los medios de comunicación asociados, de un tiempo a esta parte, a las ya no tan nuevas tecnologías de la información y la comunicación (TICs).

La noticia es, por lo visto, un tipo de discurso público capaz de transmitir y reproducir ideologías. Según Teun van Dijk (2003), los discursos son vitales para expresar y reproducir ideologías en y del diario vivir. Para entenderlas es importante ver cómo éstas pueden marcar, determinar y construir distintos niveles y estructuras discursivas:

“[...] los nexos entre discurso e ideología son mutuos. Las ideologías influyen en lo que decimos y cómo lo decimos, pero lo contrario también es cierto: adquirimos y modificamos las ideologías al leer y escuchar grandes volúmenes de información oral y escrita. Las ideologías no son innatas, sino que se aprenden, y el contenido y la forma de este discurso pueden formar, con más o menos probabilidad, modelos mentales de representaciones sociales e ideologías" (van Dijk 2003: 79).

Como parte del imaginario social legitimado al que accede la gran mayoría de las personas, se hace importante estudiar las noticias para saber qué tipo de mensajes ideológicos y segregadores se hacen presentes en las entregas informativas. En este detalle se detendrá dicha propuesta y, en particular, en cómo se pueden representar noticias en dos periódicos de circulación nacional (El Mercurio y La Tercera) sobre acontecimientos y hechos vinculados en lo político y en lo social con el vecino país de Bolivia dentro de un período de tiempo determinado (junio 2008). Si bien los medios de comunicación no son los únicos culpables, éstos deben asignarse en este afán autocrítico que se defiende- un porcentaje de responsabilidad debido a esa carga negativa que se puede vislumbrar "entre las líneas" de sus páginas. Discriminación dotada de todo aquello que se presenta como diferente y ajeno a nuestra supuesta construcción cultural (Rodrigo 1999). La respuesta social a este aparato ideológico se puede traducir en prejuicios, estereotipos, etnocentrismo, etc., en desmedro de grupos minoritarios o culturas determinadas que quedan en el afuera a partir de la soberbia construcción de un Estado-nación centralista, interno y más que autocrítico- autorreferente. Es el amén de los medios con los gobiernos en un acercamiento a la anulación total del hacer crítica y optar por un limbo del "todo bien" y del "todo pasando". Estatus que, en la actualidad, se ve conceptuado como una democracia que se define bajo esta posición, sólo por el acto de sufragar y no por una política de fondo que haga de la participación ciudadana un ejercicio de democracia en diálogo y no vigilada por el poder mediático y su alianza con el discurso de autoridad. 


\section{Hacia un periodismo intercultural}

La realidad se construye socialmente en condiciones de movilidad y mutabilidad permanente. La construcción de la realidad no es estática: varía y cambia constantemente tal cual como lo hacen las sociedades contemporáneas a partir, por ejemplo, de los incesantes fenómenos migratorios. Sin embargo, todo acto de "construcción” implica un grado de artificialidad dentro de su forma de "construir" sociedad. En cambio la mutabilidad en la comunicación humana se asocia con el estado natural en ocasiones impredecible e inesperado. La objetividad en lo social pretende construir algunos discursos objetivos que se van transformando, poco a poco, en "realidades objetivas". Como ya se precisó, un aliciente significativo en este respecto es el de los medios de comunicación. Los discursos y las representaciones sociales y culturales presentes en las noticias se van estacionando temporalmente y petrificando en nuestras conciencias hasta que las podemos llegar a asumir como la única y gran verdad, alejándose de las constantes de cambio que le caracterizan. Berger y Luckmann (1972) miran este tema desde el valor que tiene dicha construcción (artificial) en el ser humano que, en constante movimiento y desarrollo, se debe ir adaptando a un medioambiente natural determinado, bajo un orden cultural y social específico mediatizado para y por él. Conjugación necesaria para su sobrevivencia social y personal: "No sólo la supervivencia de la criatura humana depende de ciertos ordenamientos sociales: también la dirección del desarrollo de su organismo está socialmente determinada” (Berger y Luckmann 1972: 68).

La realidad es construida socialmente por los individuos. Ellos mismos, a su vez, son construidos y modelados por esta realidad social. El solo hecho de construirla le quita valor factual a esa misma realidad y la hace menos objetiva, artificializándola y quitándole fuerza a la verdad de la realidad, muchas veces institucionalizada y legitimada como "realidad suprema".

Con esto no se está responsabilizando a las noticias de activar discriminaciones explícitas en contra de las minorías, sino más bien, aclarando que los discursos de los medios están recubiertos por estructuras institucionales, discursos oficiales de autoridad, que excluyen voces, estéticas y representaciones concretas (Shohat y Stam 2002) en los cuales se podrían incluir, en un ejercicio de periodismo intercultural, las diferencias socio-culturales.

Hay que entender al periodista como "[...] una especie de lector privilegiado de acontecimientos, a partir de los cuales va construyendo mundos posibles que luego transmitirá al auditorio" (Rodrigo 1989: 187). El periodista, por tanto, es el autor de un mundo posible que logra develarse en formato de noticia. En el periodista -y en la injerencia que en éste tenga el medio para el cual se desempeña- está la decisión sobre qué tipo de mundo presentará en sus construcciones noticiosas y cómo llegará a dilucidar esos otros mundos posibles. Sin duda, un desafío para lo que Estrella Israel (2000) llama periodismo intercultural: 
"El código deontológico de los periodistas catalanes en sus criterios recomienda 'actuar amb especial responsabilitat i rigor en el cas d'informacions o opinions amb continguts que puguin suscitar discriminacions per raons de sexe, raça, creences o extracció social i cultural, així como incitar a l'ús de la violencia...', evitando expresiones o testimonios vejatorios o lesivos para la condición personal de los individuos y su integridad física o moral. El 9 de octubre de 1993, los jefes de estado y de gobierno de los estados miembros del Consejo de Europa se reunieron en la cumbre de Viena. En la declaración aparece una petición a los profesionales de los media para que presenten sus reportajes y comentarios sobre los actos racistas y de intolerancia sobre hechos (factuelle), de un modo responsable y anima a la elaboración de códigos deontológicos profesionales que reflejen estas exigencias. Aunque las intenciones pueden 'olvidarse' en la cotidianeidad” (Israel 2000: 7-8).

\section{Comunicación e interculturalidad en los medios}

La comunicación intercultural es un concepto relativamente nuevo (segunda mitad del siglo XX) y su estudio y análisis se comienza a justificar en el momento en que tienen que relacionarse dos o más personas de culturas diferentes: “[...] la comunicación intercultural ha existido siempre que dos personas, que se percibían a sí mismas como pertenecientes a culturas distintas, se han intentado comunicar” (Rodrigo 1999: 19). Entonces, se puede decir que la comunicación intercultural la conforman todas las relaciones inter, las dinámicas de interacción entre las diferentes culturas que coexisten en un mismo espacio, ya sea éste real, mediático o virtual. Para Estrella Israel (2001), por su parte, la comunicación intercultural es un reto de convivencia y tolerancia entre los seres humanos y, para que esto se logre de manera eficaz, requiere de varias características como son: cooperar para crear una atmósfera que estimule la reciprocidad y el entendimiento entre las diferentes culturas; sensibilidad a las diferencias culturales y una apreciación de la singularidad cultural; tolerancia para las conductas de comunicación ambiguas; deseo de aceptar lo inesperado; flexibilidad para cambiar o adoptar alternativas y expectativas reducidas respecto a una comunicación efectiva y directa.

Al estudiar los procesos de interacción entre culturas dispares, suele suceder algo que se conoce como “choque cultural”. Además de no comprender el comportamiento y pensar ajeno por un desconocimiento de códigos compartidos, se producen malentendidos y brota una serie de actitudes negativas hacia los otros, de desconfianza, miedo, intolerancia e incomodidad. Esto se torna en un no-diálogo que se pierde en los subterfugios de los fenómenos de incomunicación, “[...] distorsiones que se producen en la representación informativa de los otros, es decir en la construcción informativa de la diferencia” (Israel 2000: 15).

El "nosotros" se concibe a sí mismo tomando como base la existen- 
cia, real o fantaseada, de "los otros". Aquellos individuos o grupos que se desvían de los parámetros de una determinada imagen de normalidad definida dentro de "mis límites" de poder, son excluidos socialmente por quienes tienden a sentirse parte de identidades superiores. Dicha apreciación sustentada, únicamente, en la construcción social que les dice que tienen ciertos atributos que esos "otros" no poseen y que, por lo mismo, son mejores. El "Mismo" es superior a "el otro".

En el cruce entre comunicación y cultura, los medios se dejan llevar notoriamente por los discursos de autoridad vigentes y dejan de lado a la diferencia cultural y hacen oídos sordos a la precisión y el detalle, sobre todo, al momento de argumentar e informar un hecho noticioso. Además, estos criterios prejuiciosos y cegados son admitidos y se reproducen con facilidad de acuerdo a la aceptación y reconocimiento del que gocen dichos medios; que se olvidan de abrir espacios de tolerancia y armonía entre los distintos actores que protagonizan una potencial "noticia". Por lo anterior, se vuelve imprescindible poner atención en cómo son tratados "los otros" en los medios de comunicación. No sólo en la forma en que se habla de las minorías, sino también en la misma selección de los acontecimientos noticiosos en los que éstos se ven involucrados.

\title{
Propuesta y aplicación metodológica (ACD)
}

Teun van Dijk (1990 y 2003) es uno de los principales representantes que estudia y aplica el Análisis Crítico del Discurso (ACD) en referencia a las migraciones y el racismo en Europa. Basada en sus trabajos se levanta esta propuesta de análisis de la prensa diaria de cobertura nacional y la representación que hacen de la diferencia boliviana y su relación con Chile. Según el propio van Dijk, el ACD funciona como una metodología cualitativa hermenéutica, como un análisis crítico de la reproducción discursiva de la dominación y la autoridad en y por la sociedad.

\begin{abstract}
“Nuestro enfoque muestra cómo se relacionan las ideologías con las relaciones cognitivas que subyacen en la producción y la comprensión de la noticia. Esto nos permite explicar al mismo tiempo la importante función de reproducción que desempeñan los medios informativos. En parte autónomos en su forma de reproducción cultural, y en parte dependientes y controlados por estructuras e ideologías sociales más amplias, los medios informativos incorporan estas estructuras e ideologías a sus propias rutinas de fabricación de noticias $[\ldots]$ y a las estructuras convencionales de sus informaciones. Como proveedores principales de discursos públicos, los medios informativos proporcionan algo más que una agenda de temas y debates públicos” (van Dijk 1990: 259).
\end{abstract}

Si se entiende el ACD como instrumento de estudio de las noticias para poder comprender los procesos de construcción de éstas y sus representaciones, en relación a los discursos de la diferencia (en este caso boli- 
viana), se precisa seguir un conjunto de pasos determinados.

En la propuesta, que se adapta a la prensa chilena, se toma como punto de partida los estudios elaborados por van Dijk para crear categorías específicas de análisis. Se aplican, por una cuestión de alcance al objeto de estudio, de lo general a lo particular (de lo global a lo local) en aspectos formales y de significados y se presentan en cuatro niveles divididos, específicamente, en dos planos. Para mayor claridad observar el siguiente cuadro de análisis:

\begin{tabular}{|l|l|}
\hline \multirow{3}{*}{ Plano Significado/texto } & Nivel temático: significados globales \\
\cline { 2 - 2 } & $\begin{array}{l}\text { Nivel de significados locales: } \\
\text { - De carácter implícito o indirecto } \\
\text { - De carácter explícito o directo }\end{array}$ \\
\hline \multirow{2}{*}{ Plano Formal/texto-contexto } & Estructuras formales sutiles \\
\cline { 2 - 2 } & Nivel Contextual \\
\hline
\end{tabular}

Al interior del primer plano (Significado/texto) se estudian aquellos significados e informaciones que podemos extraer del texto, ya sea en forma explícita o por medio de una búsqueda más exhaustiva. En el Nivel temático de los significados globales se pregunta sobre cuáles son los temas a los que se le da importancia en la noticia, para intentar encontrar el “qué” y el “cómo” de la noticia y describir la manera en que lo realiza. Para este nivel, la tarea se facilita debido a la estructura de "pirámide invertida" utilizada por los periodistas que sintetiza lo más importante (como un resumen) en el titular (encabezado, lid, bajada, epígrafe) de cada noticia.

Dentro del nivel de los significados locales se examina el sentido de las palabras y se proponen, además, dos categorías de análisis: implícito y explícito. En los significados implícitos se revisa el contenido que no se presenta explícitamente, sino, más bien inferido: construcciones literarias que conllevan otras intenciones como implicaciones, presupuestos, alusiones, ambigüedades, hipérboles, etc. En cambio, en los significados explícitos se busca lo evidente: aquellas construcciones lingüísticas que se expresan y se dejan ver con claridad en la noticia. Las palabras que se ocupan y cómo se ocupan. Por qué se eligió esa palabra y no otra.

En el segundo plano, el Formal/texto-contexto, la preocupación se detiene en el ambiente en el cual la noticia se desarrolla y los efectos que desencadena en el público. En las estructuras formales sutiles la idea es descubrir qué tipo de discurso ideológico se hace presente en el texto pero sin que éste esté explicitado. Se pretende conocer aquellas imágenes men- 
tales, prejuicios o estereotipos que se activan a partir de la información emitida.

Por otro lado, en el nivel contextual el principal interés es descubrir dónde se encuentran las raíces de estas estructuras mentales, conocer por qué se piensan de una manera determinada esos "los otros".

Teniendo como base esta matriz de análisis, se estudiaron las noticias de los diarios El Mercurio y La Tercera, durante el mes de junio de 2008. Para ello se seleccionaron informaciones de las secciones Internacional y Nacional de El Mercurio y Política, Mundo y Nacional de La Tercera.

\section{Ejemplo de análisis}

El Mercurio, 22 de junio de 2008

Votaciones regionales y nacionales:

Bolivia y sus cruciales consultas populares para salir del pantano

Tarija, la gran reserva boliviana de hidrocarburos, somete hoy al voto popular la ratificación de la autonomía, y de ahí todos esperan el referéndum revocatorio del 10 de agosto, donde Evo Morales y los prefectos buscarán mantener sus puestos.

Gaspar Ramírez

Cada cierto tiempo se dice que "Bolivia enfrenta una decisiva semana”, o días, o proceso, o algo por el estilo. Ahora comienza uno de verdad: hoy, en Tarija, se realiza el último de los cuatro referendos autonómicos regionales, y a continuación los actores protagónicos se prepararán para la gran consulta del 10 de agosto, donde el Presidente Evo Morales y los poderosos prefectos (gobernadores) someterán sus cargos a votación popular.

La difícil tarea de fondo -que durante meses han tratado de alcanzar sin éxito gobierno y oposición- es compatibilizar la nueva Constitución boliviana con las aspiraciones autonómicas de varios departamentos. Podría pensarse: "pero si es cosa de ponerse de acuerdo", pero no, la situación es compleja. Una teleserie con historias cruzadas, conflictos eternos y personajes que sólo quieren el triunfo. Acá, una explicación para que tenga claro lo que está en juego.

El nuevo texto constitucional fue aprobado el pasado 9 de diciembre, en una polémica sesión de la Asamblea Constituyente que contó sólo con representantes leales al Presidente Evo Morales. El resultado: un documento de corte indigenista que contiene muchos de los puntos que rechazaba la oposición.

Por el otro lado, tras diálogos fallidos entre el Gobierno y las regiones opositoras, el 2 de febrero, Rubén Costas, prefecto de Santa Cruz, llamó a un referéndum departamental para aprobar el estatuto 
de autonomía. El día: 4 de mayo recién pasado.

En Beni, Pando y Tarija siguieron el mismo camino. En todas triunfó la autonomía, pero el gobierno dice que los resultados no son válidos. Evo llamó al proceso "una fiesta ilegal y anticonstitucional”.

Poco importó en las regiones. El 15 de mayo, Santa Cruz declara su autonomía, proclama vigente su estatuto, y Costas, hasta entonces prefecto, se autoproclama "gobernador".

Morales, por su lado, impulsó otra consulta popular. El llamado referéndum "revocatorio" fue propuesto a fines de 2007, cuando el foco de conflicto era la empantanada Asamblea Constituyente.

El proyecto quedó en el Senado -controlado por la oposición-, que, sorpresivamente, a comienzos de mayo la aprobó. Aquí entra Tarija. El departamento que guarda el 85\% de las reservas de gas del país buscará ratificar hoy el estatuto autonomista y así controlar los ingresos por la venta y exportación del energético.

Evo se tiene fe, y esta semana aseguró que será ratificado con más del 54\%, porcentaje con el que en diciembre de 2005 alcanzó la Presidencia. Pero va más allá. Asegura que tras el 10 de agosto cambiará el mapa político con la salida de prefectos opositores (seis de los nueve). "Ojalá todos. Así no habrá una tranca, así no habrá bloqueadores de este proceso de cambio", indicó.

Su idea es clara. La oposición tiene mayoría en el Senado y la paridad de fuerzas tuvo entrampada la Constituyente. Pero, sobre todo, los departamentos mencionados, que generan el 45\% del PIB del país, son los más tenaces detractores de Morales. Él quiere un triunfo claro para borrar la oposición. Al otro lado quieren el escenario contrario.

Las encuestas dan triunfador a Evo, pero también a Costas, el prefecto cruceño, uno de sus grandes "enemigos".

Para Ricardo Díaz, senador del MAS (Movimiento Al Socialismo, agrupación de Morales), tras el referéndum, "los diferentes actores políticos podrán cambiar de percepción de la realidad que vive el país y la necesidad de juntar voluntades para alcanzar un mayor desarrollo y bienestar".

Mientras, en paralelo, ambas partes intentaban compatibilizar el proyecto constitucional con los estatutos autonómicos. Tratando de ayudar, los gobiernos de Argentina, Brasil, Colombia; la OEA y la Iglesia Católica boliviana enviaron delegados. Pero nada. El 11 de junio, el gobierno suspendió los diálogos hasta después del 10 de agosto. Para entonces, Morales espera una nueva correlación de fuerzas. De más está decir que una que sea aún más favorable a él. Las urnas, otra vez, tienen la palabra.

Evo no puede moverse (recuadro interior)

Entre tanto referéndum, ha cundido el enojo en Bolivia. Tal es así que el propio Presidente Evo Morales tiene problemas para acudir a 
actos públicos. En dos meses, manifestaciones en cuatro regiones se lo impidieron. Ante el temor de que se vuelva una tendencia, el Gobierno anunció el miércoles que tomará acciones para garantizar el libre tránsito del Jefe de Estado.

Es que para el gobierno, la cosa fue mucho: esta semana, por tercera vez en seis días, se vio forzado a suspender un acto oficial debido a la presión popular que rechaza su presencia. No pudo llegar a la capital de Tarija.

El 24 de mayo, se quedó con las ganas de arribar a Sucre. Lo mismo le sucedió en una localidad de Santa Cruz. Hace un mes, el ministro de la Presidencia, Juan Ramón Quintana, tampoco pudo llegar a Riberalta, en Beni. Para el senador Róger Pinto, del opositor Podemos, Morales no es bienvenido en Pando. "Sin lugar a dudas, creo que el Primer Mandatario ha hecho muchos méritos para que el pueblo pandino le niegue la llegada a esta capital de don Evo Morales”.

\section{Aplicación de la matriz}

Titular:

Epígrafe: Votaciones regionales y nacionales.

Título: Bolivia y sus cruciales consultas populares para salir del pantano.

Bajada: Tarija, la gran reserva boliviana de hidrocarburos, somete hoy al voto popular la ratificación de la autonomía, y de ahí todos esperan el referéndum revocatorio del 10 de agosto, donde Evo

Morales y los prefectos buscarán mantener sus puestos.

\begin{tabular}{|l|l|}
\hline $\begin{array}{l}\text { Fecha: } \\
\text { 22 junio } 2008\end{array}$ & $\begin{array}{l}\text { Página/Sección: } \\
\text { A6/Internacional }\end{array}$ \\
\hline $\begin{array}{l}\text { 1.- Plano } \\
\text { Significado/texto }\end{array}$ & $\begin{array}{l}\text { Nivel temático: significados globales } \\
\text { Se realiza el último de los referendos autonómicos } \\
\text { en el departamento de Tarija, en Bolivia. Luego de } \\
\text { esta votación, los bolivianos participarán del } \\
\text { referendo revocatorio, preparado para el 10 de agos- } \\
\text { to, en donde decidirán la permanencia del Presidente } \\
\text { Evo Morales y los prefectos en sus cargos. } \\
\text { La tarea del Gobierno es compatibilizar la nueva } \\
\text { constitución boliviana con las aspiraciones autonó- } \\
\text { micas de varios departamentos. } \\
\text { La importancia de la votación en Tarija radica en } \\
\text { que es el departamento que posee el 85\% de las re- } \\
\text { servas de gas del país. } \\
\text { Evo aseguró que será ratificado con más del 54\%, } \\
\text { lo que también aseguran las encuestas. Pero igual- }\end{array}$ \\
\hline
\end{tabular}


mente dan por triunfador a Rubén Costas, prefecto de Santa Cruz, uno de los grandes enemigos del mandatario, y quién inició los referendos autonomistas.

Llama la atención que la realidad actual de Bolivia se compare con un pantano: su política está estacada, el país está paralizado, no puede avanzar, progresar.

Nivel de significados locales:

- De carácter implícito o indirecto

Bolivia y sus cruciales consultas populares para salir del pantano: Bolivia se presenta como un país atrapado, empantanado dentro de una situación incómoda de la que le costará mucho salir. Los referendos y las consultas populares tal vez podrían ayudarlos. Pero no se asegura nada.

El resultado: un documento de corte indigenista que contiene muchos de los puntos que rechazaba la oposición: Se culpa a la postura indigenista de las políticas de Morales por el estancamiento de Bolivia en esta "crisis pantanosa", de la que no puede escapar. Evo no puede moverse (en recuadro): Se indica que dentro del conflicto interno que aqueja a Bolivia, su mandatario no puede hacer nada al respecto. Se encuentra atrapado en este "pantano", no puede moverse, no puede tampoco mejorar la situación de su país.

[...] ha cundido el enojo en Bolivia. Tal es así que el propio presidente Evo Morales tiene problemas para acudir a actos públicos (en recuadro): Se nos indica que la tensión social está llegando a un punto tan crítico que el propio Presidente de Bolivia no puede acudir a los actos públicos, porque los manifestantes se lo han impedido. El riego es tal que se teme que se produzca un linchamiento.

- De carácter explícito o directo:

Cada cierto tiempo se dice que "Bolivia enfrenta una decisiva semana”, o días, o proceso, o algo por el estilo. Ahora comienza uno de verdad: En esta cita se menosprecia por completo la situación por la que pasa Bolivia. Se lo transforma en un "algo", cualquier cosa sin mucha importancia.

[...] la situación es compleja. Una teleserie con historias cruzadas, conflictos eternos, y personajes que sólo quieren el triunfo: Bolivia se encontraría en una 


\begin{tabular}{|c|c|}
\hline & $\begin{array}{l}\text { situación de crisis política y social que es tan com- } \\
\text { plicada que se le da el tenor de melodramática y } \\
\text { hasta ridícula, comparándola con una telenovela. El } \\
\text { periodista indiscutiblemente utiliza el término } \\
\text { "teleserie" de manera despectiva. }\end{array}$ \\
\hline \multirow[t]{2}{*}{$\begin{array}{l}\text { 2.- Plano } \\
\text { Formal/ } \\
\text { texto-contexto }\end{array}$} & $\begin{array}{l}\text { Estructuras formales sutiles } \\
\text { Bolivia se presenta inmersa en una crisis social y } \\
\text { política, con un mandatario incapaz de mantener el } \\
\text { control y sacar adelante al país. } \\
\text { Se muestra a los bolivianos como personas violen- } \\
\text { tas, poco civilizadas. }\end{array}$ \\
\hline & $\begin{array}{l}\text { Nivel Contextual } \\
\text { El conflicto entre Chile y Bolivia nace en el siglo } \\
\text { XIX, por el dominio sobre el salitre, recurso que } \\
\text { ocupaba un lugar muy importante en la economía. } \\
\text { Esto desencadenó en un conflicto bélico que } \\
\text { involucró también a Perú, conocido como la Gue- } \\
\text { rra del Pacífico (1879-1884). } \\
\text { En la memoria colectiva chilena aún vive el senti- } \\
\text { miento de rencor hacia los bolivianos, primero como } \\
\text { "patrones despiadados" en Antofagasta (donde mu- } \\
\text { chos chilenos iban en busca de oportunidades de } \\
\text { trabajo), y luego como "enemigos bélicos". Esta } \\
\text { odiosidad ha sido alimentada durante generaciones, } \\
\text { a través de relatos populares y de los propios libros } \\
\text { de historia, entre otros. Actualmente la situación que } \\
\text { presenta esta noticia, muestra a Bolivia como ene- } \\
\text { migo, y las crisis por las que pasan se traducen en } \\
\text { una especie de karma: un castigo por sus acciones } \\
\text { anteriores. }\end{array}$ \\
\hline
\end{tabular}

\section{Resultados generales}

Durante el mes de junio de 2008, ocho fueron las noticias publicadas entre ambos diarios. La mayoría de éstas es alusiva a la crisis política del país. Una de ellas es el ejemplo desarrollado anteriormente.

\begin{tabular}{|l|l|l|}
\hline El Mercurio & 4 noticias & $\begin{array}{l}\text {-Mundo: } 3 \\
\text {-Nacional: } 1\end{array}$ \\
\hline La Tercera & 4 noticias & $\begin{array}{l}\text {-Internacional: } 3 \\
\text {-Nacional: } 1\end{array}$ \\
\hline
\end{tabular}


En general, se puede notar cómo, en todas las noticias, la imagen de Chile se ve ensalzada en oposición a la de Bolivia, que se presenta siempre como un país envuelto en una complicada crisis política y social, expuesta contextual e históricamente como resultado de un pobre nivel cultural, producto de una educación precaria. Se muestra a "el otro" boliviano como poco desarrollado, en comparación con los chilenos. Por otra parte, se expone a la clase política del país andino, al poner el énfasis en las figuras del Presidente Evo Morales y del Canciller David Choquehuanca como ineficientes e incapaces. Como ejemplo, en la noticia del 22 de junio del diario El Mercurio, se hace referencia al fracaso político de Evo Morales al mando de Bolivia, y cómo los pobladores rechazan su presencia por medio de manifestaciones. La situación llegaría a tal extremo que se teme por su seguridad: "Entre tanto referéndum, ha cundido el enojo en Bolivia. Tal es así que el propio Presidente Evo Morales tiene problemas para acudir a actos públicos. En dos meses, manifestaciones en cuatro regiones se lo impidieron”.

\section{Plano significado/texto}

Nivel temático: significados globales: En esta categoría, se revisaron los tópicos que más se repiten en las noticias. A primera vista, se descubrieron representaciones negativas y discriminatorias para con la sociedad boliviana. Se encontraron temas referidos a la "mirada" que como chilenos tenemos de "los otros": los bolivianos y la situación de su país a la distancia. Los temas que se destacan son: política, las figuras de Evo Morales y David Choquehuanca, los referendos autonomistas, crisis social y económica y el mar para Bolivia.

Nivel de significados locales:

- De carácter implícito o indirecto: Aquí es donde se encuentra la mayoría de las construcciones discriminatorias sobre los bolivianos. Se toma como negativa su imagen en El Mercurio y en La Tercera, pero nunca se hace de manera directa. En las noticias analizadas, lo que se quiere decir no se hace de forma evidente. Se debe poner atención a todos los detalles del texto para encontrar las construcciones negativas. Por ejemplo:

\section{-Título: Parlamentarios piden a Foxley explicar acuerdo maríti- mo con Bolivia}

“[...] encargar "estudios técnicos” para el tema marítimo- provocó sorpresa y fuerte inquietud entre los personeros políticos de Santiago” (La Tercera, 20 de junio de 2008).

Si bien hay una parte del gobierno chileno que quiere avanzar en las relaciones con Bolivia, la gran mayoría de los políticos se niega. Son especialmente tajantes cuando se trata del conflicto marítimo. Aunque se está hablando de realizar estudios técnicos, sin que todavía exista ninguna decisión de ceder mar o lograr un acuerdo de por medio. El Senado y la Cámara 
de Diputados de Chile se muestran molestos por la mejora en las relaciones. Se aprecia cómo la clase política exterioriza su falta de unión, además de su obvia animadversión con Bolivia.

- De carácter explícito o directo: Se refiere a construcciones que tratan de manera negativa a "el otro" y presentan claras intenciones ideológicas. Por ejemplo:

\section{- Título: Bolivia y sus cruciales consultas populares para salir del pantano}

"Podría pensarse: “pero si es cosa de ponerse de acuerdo”, pero no, la situación (de Bolivia) es compleja. Una teleserie con historias cruzadas, conflictos eternos y personajes que sólo quieren el triunfo” (El Mercurio, 22 de junio de 2008).

\section{Plano formal/texto-contexto}

Estructuras formales sutiles: En esta categoría se buscan las construcciones noticiosas que remiten a ciertas estructuras mentales negativas. En este sentido, las imágenes que se asocian a Bolivia son:

País inestable, en crisis social, política, y económica.

Líder incapaz de manejar o mejorar la situación de su país.

Ignorancia, incultura.

Nivel contextual: Se perciben las raíces de las construcciones negativas que se tienen de "los otros", de los bolivianos. Siguiendo esta línea, se puede ver que la imagen discriminatoria de este vecino país, ha venido arrastrándose hace más de un siglo, desde la guerra del Pacífico (18791884) cuando Bolivia, Perú y Chile se enfrentaron por el dominio del salitre en el norte de este último país y en el centro occidente de Bolivia. La imagen de los bolivianos "enemigos" ha continuado alimentando nacionalismos y chovinismos que, en este momento, continúan reproduciéndose a través de los diarios El Mercurio y La Tercera.

En consecuencia, con este análisis, se permite deducir que la imagen negativa que se presenta de Evo Morales hace referencia, más que a sus verdaderas capacidades, a su ideología política socialista e indigenista, teniendo en cuenta que El Mercurio y La Tercera son diarios tradicionales y conservadores, tal cual como la prensa chilena en general.

\section{Conclusiones}

Las otras culturas estudiadas son invalidadas por las notas periodísticas ya que éstas tienen una gran carga ideológica (van Dijk, 2003). "El otro" se ve suprimido por los prejuicios y estereotipos que aparecen en las 
estructuras de las noticias y que son, a su vez, traspasados, mantenidos y recreados por los lectores a quienes llegan los diarios. De esta manera, se plasma en sus páginas una visión de mundo que conviene y atrae a los intereses económicos y políticos dominantes del país, que continúan expandiendo su discurso discriminatorio y descalificador hasta convertirlo en una realidad social. Sin considerar las políticas en cuanto a derecho internacional propias del país analizado y con un estudio “objetivo” desde la mirada institucional y local chilena que, en este caso particular, no asimila otros puntos de vistas, formas de actuar y determinaciones socio, políticas y culturales.

Aunque muchas veces no hay conciencia, los medios de comunicación analizados en Chile no ejercen un periodismo intercultural como el esbozado en el desarrollo de este artículo y cargan a sus discursos noticiosos de contenido ideológico, acomodando la información a sus propios intereses, entregando cargas negativas o simplemente suprimiendo actores sociales concretos. En este sentido, los medios condicionan y predisponen a sus lectores a ciertas actitudes a la hora de interactuar con grupos y culturas diferentes. En este caso particular: Bolivia. Los medios de comunicación no cooperan en mejorar las relaciones interculturales entre y con sus países limítrofes. Es más, muchas veces provocan mayores desencuentros y conflictos e imponen a los lectores sus propias concepciones estereotipadas y cegadas por una carga ideológica, ya sea que provenga de la empresa informativa, con una línea editorial determinada, o a través de percepciones del propio reportero. El periodismo en la actualidad debería reconocer la riqueza y diversidad cultural del mundo, para dotar de expresión y de poder a las minorías y, en general, a todos los actores que participan en las noticias. Así podría acercarse a un necesario y urgente de implementar, enseñar y consolidar periodismo intercultural. 


\section{Bibliografía}

Berger, P. y Luckmann, Th. (1972), La construcción social de la realidad, Amorrortu, Buenos Aires.

Israel Garzón, E. (2000), “Bases para el periodismo intercultural”, en Revista Latina de Comunicación Social $\mathrm{N}^{0}$ 34, Barcelona. Disponible en: http://www.ull.es/publicaciones/latina/aa2000kjl/w34oc/43estrella.htm, 6 de septiembre de 2008.

Idem (2001), "Intercultural Communication For A Journalism Of The Difference”, en Ecuador 2002 - Comunicación-Incomunicación. Disponible en http://www.portalcomunicacion.com/bcn2002/n_eng/programme/ prog_ind/papers/g/pdf/g001_garzo.pdf, 6 de septiembre de 2008.

Rodrigo, Alsina, M. (1989), La construcción de la noticia, Paidós, Barcelona.

Idem (1997), “Elementos para una comunicación intercultural”, en Revista Cidob d'afers Internacionals, No 36, Barcelona. Disponible en: http:// www.cidob.org/es/content/download/5783/55624/file/36rodrigo_cast.pdf, 22 de septiembre de 2008.

Idem (1999), Comunicación Intercultural, Anthropos, Barcelona.

Sierra, F. (1999), Elementos de Teorías de la Información, MAD, Sevilla.

Shohat, E. y Stam, R. (2002), Multiculturalismo, cine y medios de comunicación. Crítica del pensamiento eurocéntrico, Paidós, Barcelona.

Van Dijk, T. (1990), La noticia como discurso: Comprensión, estructura y producción de la información, Paidós, Barcelona.

Idem (2003), Ideología y discurso, Ariel, Barcelona.

Vázquez Medel, M. A. (2003), Teoría del Emplazamiento. Aplicaciones e implicaciones, Alfar, Sevilla. 